\title{
TRANSAÇÃO E REMISSÃO
}

\section{(PARECER)}

\author{
Altino Portugal Soares Pereira \\ Professor Catedrático da Faculdade de Direito \\ da Universidade do Paraná.
}

Segundo os têrmos da consulta formulada, o Engenheiro Civil A ajustou com a Fundação B a a construção de uma estrada, que, depois de concluída, foi vistoriada pelos assistentes técnicos da presidência da aludida Fundação e pela mesma aceita. Para a execução dos trabalhos, houve autorização verbal dos administradores, confirmada por uma ordem de serviço, datada de 26 de janeiro de 1959, que tomou o número nove (9). O preço dos serviços a serem prestados com a execução da obra aludida, deveria ser pago com base na tabela em vigor do Departamento de Estradas de Rodagem do Estado "após entrega, recebimento e parecer da assistência técnica da "Fundação". Como adiantamento de parte do preço, o Engenheiro Civil A recebeu, pessoalmente, a quantia de Cr\$2.100.000,00 (dois milhões e cem mil cruzeiros), de que deu quitação. Mas, por ocasião da entrega da obra, verificouse ter, direito, ainda, ao pagamen- to restante de Cr\$3.410.000,00 (três milhões, quatrocentos e dez mil cruzeiros), consoante a Ordem de Serviço n. ${ }^{\circ}$, já mencionada.

Tendo necessidade de se manter distante desta Capital, para, no interior do Estado, executar a obra contratada, o Engenheiro Civil A, em data de 19 de março de 1959, constituiu seu procurador C. Do respectivo mandato constam:

"poderes amplos e ilimitados para representar o outorgante junto à Fundação B, nesta Capital, em tudo que disser respeito à construção da estrada de rodagem constante de discriminação que adiante se expressa, como tudo está na Ordem de Serviço n. ${ }^{9} 9$, podendo requerer o que convier, assinar contratos, têrmos e demais documentos, receber em parcelas ou no todo o preço respectivo, dar recibos e quitações, TRANSIGIR, fazer cessões de crédito e tudo prati- 
car para o perfeito desempenho dêste mandato, inclusive substabelecer".

Usando do mandato que lhe fôra outorgado, o procurador $\mathbf{C}$ chegou a formular requerimento de próprio punho à Fundação B, solicitando o pagamento do restante do preço da construção, devido ao Engenheiro Civil $\mathbf{A}$, no montante de Cr\$3.410.000,00 (três milhões, quatrocentos e dez mil cruzeiros). Posteriormente, porém, numa atitude insólita, dito procurador, SEM NADA RECEBER (é o que se infere da Consulta), assinou o têrmo seguinte:

"Têrmo de composição amigável. Aos doze dias do mês de novembro do ano de 1959 , na sala da Presidência da Fundação B, no enderêço supra, onde presentes se achavam o Senhor G, Presidente da Fundação, o Senhor C, brasileiro, casado, industrial, como procurador bastante do Engenheiro Civil A, conforme procuração passada em notas do ...Tabelião, desta Cidade, às fls.... do livro..., os Advogados Drs. J e D, foi dito pelo Senhor C, como procurador do Engenheiro Civil A, que pelo presente e na melhor forma de direito, declarava, como declarado tem, que dá rasa e geral quitação à Fundação $\mathbf{B}$, de todo e qualquer crédito ou direito que tenha até a data presente e também e especialmente, com relação em tudo que disser respeito à estrada por êle (Engenheiro Civil A) construída, que se inicia no local constante de discriminação expressa, cuja construção foi autorizada pela Ordem de Serviço n. ${ }^{\circ}$ 9, do corrente ano, expedida pela Fundação B; outrossim, declara estar de acôrdo com a Portaria n. ${ }^{\circ}$ 64, da referida Fundação, que tornou sem efeito a Ordem de Serviço n. ${ }^{\circ}$ 9, já mencionada. Diante disso tudo, fazia tal declaração, para os fins e efeitos legais, inclusive para que não seja considerado como existente o pedido feito pelo protocolo n. ${ }^{\circ}$ 403/59, da Fundação B, que fica nulo e de nenhum efeito diante desta ampla e irrestrita quitação que envolve todos os negócios tidos com esta Fundação pelo Engenheiro Civil A. Pelo Presidente da Fundação, foi dito que aceita esta declaração e quitação ampla, por ser a expressão da verdade. Êste têrmo vai assinado pelas partes, diante de duas testemunhas, para que, em qualquer tempo, surta efeitos de direito. Assinados) etc.".

Referidos êstes fatos, pergunta o consulente:

"1 - Nos poderes do mandato outorgado, compreende-se 0 de realizar composição amigável, como foi efetivada?

2 - Os poderes de renunciar direitos ou remitir dívidas constituem poderes especiais ou estão compreendidos nos poderes de receber e transigir?

3 - Com a procuração que lhe foi outorgada, podia o mandatário, através do têrmo que assinou, liberar, inteiramente, o devedor, no caso, a Fundação B, de sua obrigação? 
4 - Uma vez considerado ineficaz o têrmo em aprêço, assinado pelo mandatário, que já requerera o pagamento do saldo da dívida, subsiste para a Fundação B a obrigação de pagar o aludido saldo?

5 - No caso de não se considerar o mandatário investido de poderes especiais para remitir dívidas, poderá a devedora, Fundação B, que não pagou o preço total da obra realizada e se locupletou com o trabalho do mandante, legar que nada mais deve por haver assinado o têrmo de composição amigável com o procurador infiel?

6 - Poderia ter qualquer eficácia a Portaria n. ${ }^{\circ}$ 64, baixada em 25-3-59, que tornou sem efeito a Ordem de Serviço n. ${ }^{\circ}$ 9, do mesmo ano, quando a construção da estrada já se chava concluída?

7 - Subsiste íntegro e irrecusável o direito do Engenheiro Civil A, de receber da Fundação $\mathbf{B}$ o saldo do preço ajustado para a construção da estrada?"

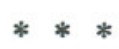

Com base no relato, aqui reproduzido, passamos a responder às perguntas formuladas.

Primeira pergunta - O chamado "têrmo de composição amigável", aqui trasladado, não encerra, em nosso entender, qualquer composição. Em resumo, o que nele se encontra é uma declaração de quitação geral, embora sem os requisitos da Lei (art. 940 do Código Civil), de envolta com uma renúncia de direitos, que sendo patrimoniais, como no caso, equivale a remissão.

Composição é acôrdo, que, no caso, não está, siquer, concebido.
Realmente, o Senhor C, alegando ser procurador do Engenheiro Civil $\mathbf{A}$, deu quitação do que êste tinha a receber na Fundação $\mathbf{B}$, e, além disso, abriu mão de direitos que postulara com o protocolado n. ${ }^{\circ} 403 / 59$ e concordou com os têrmos de uma Portaria, que tornou sem efeito Ordem atinente a obras já realizadas e recebidas pela mencionada Fundação. Esta se limitou a aceitar as declarações constantes do têrmo, porém, nada concedeu ao Engenheiro Civil A, a nada se obrigou para com êle.

Com êstes esclarecimentos, podemos asseverar que os atos praticados pelo procurador $\mathbf{C}$, no "têrmo de composição amigável", não se acham compreendidos nos poderes que lhe foram outorgados pelo Engenheiro Civil A.

O mandatário referido tinha poderes para requerer, assinar têrmos, documentos, receber, dar recibos e quitações, transigir, fazer cessões de crédito e tudo praticar para o perfeito desempenho do mandato. Êste, porém, originou-se do interêsse que tinha o mandante em auferir as vantagens decorrentes do ajuste celebrado com a Fundação. $\mathrm{E}$ o principal interêsse era receber o preço da obra. Aliás, êste objetivo se identifica com o que foi visado pelo mandante, quando se comprometeu a construir a estrada. Não fôsse isto, não teria sido outorgado o mandato.

Pois, bem. Pelo chamado "têrmo de composição amigável", fêzse, justamente, o contrário do que visou o mandante. Seu escôpo foi receber, mas seu procurador abriu mão de todos os direitos decorrentes do contrato e atinentes à execução da obra avançada, que foi 
concluída, vistoriada e aceita. Se o objetivo do mandante, dando os poderes que deu, era de receber o preço da obra, não se justificam, de nenhum modo, a renúncia, a cessão gratuíta, enfim, qualquer liberalidade. Tais atos contrariam a causa do ato jurídico inicialmente celebrado, em razão do qual existia o mandato.

Indiscutivelmente, todo ato jurídico tem uma causa, que se distingue mesmo da simples manifestação da vontade das partes. No caso, para a Fundação, a causa é a entrega da obra; para o Engenheiro Civil A, o recebimento do preço. E a causa final, o escopo de ambas as partes. Não é outra a lição dos mestres (Alberto Trabucchi, Istituzioni di Diritto Civile, páginas 158/166).

De tal arte, quando o mandante outorgou poderes para dar quitação, òbviamente pressupunha o recebimento do preço estipulado. Nem podia ser de outro modo, pois, se quisesse que o mandatário renunciasse, remitisse dívidas, não lhe teria conferido poderes para receber o preço da obra e praticar atos correlatos com o recebimento.

Ademais, a quitação firmada pelo referido mandatário não alude a qualquer pagamento, mesmo porque êste não foi efetuado. O mandatário deu quitação e declarou estar de acôrdo com o desfazimento das obrigações da Fundação, tornando sem efeito a Ordem de Serviço n. ${ }^{\circ}$ 9, considerando nulo o protocolado n. ${ }^{\circ} 403 / 59$, em que, antes, havia pedido o pagamento do saldo do preço devido ao Engenheiro Civil A. Assim, praticou ato de renúncia.

O têrmo quitação, no caso, é um eufemismo com que se emoldura o ato praticado pelo procurador $\mathbf{C}$, nos poderes que the foram outorgados. Chamou-se quitação a uma renúncia e esta foi aceita porque o procurador tinha poderes para dar quitação... Contudo, os têrmos jurídicos só se devem usar com seu significado técnico. E quitação é prova de pagamento (art. 940 do Código Civil).

É de se admitir que o mandatário com poderes para receber possa dar quitação, mesmo sem poderes para tanto, visto como quem paga tem direito a quitação. O que se não admite, porém, é que o mandatário tenha dado quitação válida, sem ter recebido o saldo da dívida e sem ter poderes para renunciá-la.

Segunda pergunta - Não há dúvida que os poderes para renunciar direitos ou remitir dívidas devem ser conferidos de modo especial.

$\mathrm{O}$ art. 1.295 do Código Civil e seu $\S 10^{\circ}$ dispõem:

"O mandato em têrmos gerais só confere poderes de administração.

$\S 10^{\circ}$ - Para alienar, hipotecar, transigir, ou praticar outros quaisquer atos que exorbitem da administração ordinária, depende a procuração de poderes especiais e expressos".

Evidentemente, os poderes para renunciar direitos ou remitir dívidas não se compreendem nos de simples administração. Segundo a lição de Clóvis Bevilaqua, "compreende-se na administração ordinária os atos de gerência, que 
não importam alienação, exceto dos bens de fácil deterioração e dos que se destinam a ser alienados" (Código Civil, vol. V. pág. 41). Da mesma forma, não se compreendem nos de receber e transigir e, podemos acrescentar, nem nos de dar quitações e fazer cessões de crédito. Todos os atos referidos diferem da renúncia de direitos, da remissão de dívidas.

Renúncia é o ato pelo qual a pessoa se despoja dos direitos que integram o seu patrimônio. Isto é noção correntia.

Remissão é uma forma de renúncia das dívidas. No dizer de $\mathrm{M}$. I. Carvalho de Mendonça, "é uma renuncia gratuita do crédito, incondicionalmente manifestada pelo credor em benefício do devedor. É, pois, uma espécie de que a renúncia é o gênero" (Doutrina e Prática das Obrigações, Tomo I, pág. 691).

Por êste meio, o credor perdoa o devedor.

Segundo Colin \& Capitant, "la remise de dette est l'abandon gratuit que le créancier fait de ses droits au débiteur" (Droit Civil Français, vol. II, pág. 125).

Para Planiol, "la remisse de dette est la renonciation du créancier à son droit" (Traité Élémentaire de Droit Civil, revu et completé par Georges Ripert avec le concours de Jean Boulanger, $3 .^{\mathrm{a}}$ ed., Tome II, pág. 640).

Não destoa dêste entendimento A. Von Tuhr, ao declarar: "la remisión no es un contrato del que nazcan simples obligationes, sino un acto de dispositión por el que el acreedor se desprende de un valor ativo de su patrimonio. En el remitente deberá concurrir, por tanto, aparte de la capacidad de obrar necesaria para todos los negocios juridicos que mermam el patrimonio, el poder de disposición sobre el crédito remitido" (Tratado de las Obligaciones, Tomo II, traducido del alemán y concordado por W. Roces, $1 .^{a}$ ed., Madrid, 1934, pág. 144).

Messineo também nos ensina: "la remissione (del debito) è un caso particolare del fenomeno della rinunzia (Cfr. retro, parag. 12 , n. 10) al diritto soggetivo. Con la remissione, infatti, il creditore rinunzia (in tutto, o in parte) al suo diritto e con ciò stesso libera (in tutto $o$ in parte) il debitore, pur non ricevendo la prestazione (con dono del debito) "Manuale di Diritto Civile e Commerciale, vol. II, Parte II, pág. 396, parag. 125, 8. ${ }^{\text {a }}$ ed., Milano, 1952.

Além dos conceitos lapidares, acima transcritos, sôbre remissão, como forma de renúncia, que é, trazemos, pela sua oportunidade, êste excerto de José Paulo Cavalcanti, que reflete a melhor lição dos mestres:

“白 frequente entenderem-se como renúncia as concessões recíprocas que as partes se fazem nas transações. Todavia, êsses sacrifícios recíprocos nada têm a ver com a renúncia, representando apenas um elemento estrutural, indispensável à configuração das transações. Com efeito, a ocorrência dessas recíprocas concessões, juntamente com a composição da lide atual ou com a prevenção da lide futura, integra a própria causa do negócio translativo, é inapartável dêste (v. g. Emílio Valsecchi, ob. cit. n. 
23, pág. 191, Dessona ob. cit., pág. 386, Alberto Trabucchi, ob. cit. n. 73, pág. 133, Henri de Page, ob. cit., tomo $\mathrm{V}, \mathrm{n}$. 483, pág. 472).

A função de composição da lide, a litigiosidade, portanto, do direito, essencial para a transação, é inteiramente estranha à renúncia; a reciprocidade de sacrifícios, que a transação supõe, não está na renúncia, em que o sacrifício é de uma só parte (Valsecchi, ob. cit., n. 35, pág. 231), sendo a transação negócio oneroso, o que é inteiramente incompatível com a renúncia" (Da Renúncia no Direito Civil - Ed. Rev. Forense, 1958, págs. 169/170).

Ainda, baseado nos mestres, afirma o mesmo autor, no referido trabalho:

"Para renunciar, o mandatário deve estar investido de poderes expressos e especiais, de acôrdo com o art. 1.295, parágrafo $1 .^{\circ}$, do Código Civil Brasileiro. Os poderes para transigir não bastam para renunciar, porque na transação há reciprocidade de sacrifícios, enquanto na renúncia o sacrifício é sòmente do renunciante" (Ob. cit., pág. 132/134).

Ora, se remissão é renúncia e se o que fez o procurador $\mathbf{C}$, mandatário no caso, foi abrir mão de direitos, renunciar, evidentemente exorbitou do mandato que lhe conferia poderes para, de acôrdo com os interêsses do mandante, receber, dar quitação, fazer cessões de crédito e transigir.

O chamado "têrmo de compo- sição amigável" encerra, de modo iniludível, uma renúncia.

No mandato outorgado pelo Engenheiro Civil A ao procurador C, porém, inexistem poderes para renunciar direitos, para remitir dívidas.

O saudoso Clóvis Bevilaqua não hesita em declarar que são necessários poderes expressos para "renunciar direitos, remitir dívidas" (Cód. Civil, vol. V, pág. 41).

De Plácido e Silva, no "Tratado do Mandato e Prática das Procurações", $2^{2}$ ed., $10^{\circ}$ vol., pág. 195 , diz:

"Remitir dívidas ou remitir obrigações é renunciar o direito de exigí-las, é perdoálas, é abrir mão das quantias ou das prestações que representam, eximindo o devedor do dever de cumprí-las ou pagá-las.

A remissão de dívidas ou de obrigações, pois, importa em alheiamento ou perda de bens que saem do patrimônio do credor-remissório. E espécie de quitação que se deriva do perdão ou da renúncia,- equivalendo a doação (são nossos os grifos). Não pode, por isso, o mandatário desfalcar o patrimônio do mandante por meio de ato jurídico, a que não esteja especialmente e expressamente autorizado".

Ao referir-se a renúncia de direitos, diz o mesmo De Plácido e Silva:

"A manifestação da vontade de renunciar, ou ceder os seus direitos, deve ser clara e positiva. 
A renúncia importa um abandono voluntário de um direito. E cessão ou alienação, a título gratuito, sem vantagens ao renunciante.

Consequentemente, justa a exigência de poder expresso e especial para sua efetivação.

Os poderes de renúncia não se encontram implícitos nos poderes para vender, nem para transigir.

Quem tem poderes para transigir, não tem para renunciar, porque a renúncia é mais do que transação; na transação há reciprocidade de concessões, o que não se dá na renúncia". (Ob. cit., pág. 196).

Segundo Carvalho Santos, entre os atos que, por exorbitarem a administração ordinária exigem poderes especiais e expressos, estão:

“d) remitir ou perdoar dívidas, por isso que ao procurador não é lícito renunciar direitos do mandante sem poderes expressos e especiais, tanto mais quanto a remissão, em regra, envolve sempre um ato de alienação ou doação (Cfr. Cândido de Oliveira Filho, ob. cit., pág. 107); e) renunciar a qualquer direito, precisamente porque a renúncia envolve, em última análise, um ato de disposição para o qual são necessários poderes especiais e expressos. Além disso, é preciso levar em conta que a renúncia é alienação a título gratuito, e como tal prejudi- cial ao mandante, de sorte que, com mais fortes razōes, se hão de exigir poderes especiais" (J. Ribeiro, ob. cit., pág. 52).

"Quem tem poderes para transigir, escreve J. Ribeiro, não tem para renunciar: porque a renúncia é mais do que transação; na transação há reciprocidade de concessões, o que não se dá na renúncia. Do mesmo modo quem possue para vender não está autorizado a renunciar; porque venda é alienação a título oneroso e a renúncia, alienação a título gratuito (Ob. cit., pág. 52)" (Código Civil Interpretado, vol. XVIII, pág. 175).

Não resta dúvida, pois, que os poderes para renunciar direitos ou remitir dívidas devem ser expressos no mandato e não estão compreendidos nos de "receber e transigir", pois são diferentes os institutos jurídicos a que os mesmos se referem.

Esta lição do inesquecível $\mathbf{M}$. I. Carvalho de Mendonça esvanece qualquer dúvida sôbre ser o chamado "têrmo de composição amigável" um ato de renúncia:

"Ordinăriamente, se não sempre, as concessões contém renúncia, desistência de direitos, cortes em pretensões, como meios de poderem as partes chegar a um acôrdo. Se tal renúncia não tiver o caráter de reciprocidade, ou há doação ou há remissão de dívida; nunca, porém, transação. Renúncia sem recompensa não é transação; é liberalidade". (Dou- 
trina e Prática das Obrigações, Tomo I, pág. 647).

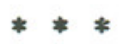

Terceira pergunta - Em face da resposta que demos a segunda pergunta, é evidente que, sem os poderes imprescindíveis para abrir mão de direitos, não podia o procurador constituido, com o mandato que lhe foi outorgado, liberar de sua obrigação a Fundação B.

Com efeito, as obrigações só se extinguem nos casos e pelas formas previstas em lei.

A quitação dada pelo referido procurador e que se expressou no chamado "têrmo de composição amigável" não decorreu de uma das causas de extinção das obrigações. A renúncia de direitos, implícita nos têrmos da mencionada quitação e expressa na declaração do mandatário $\mathbf{C}$, de anular o protocolado n. ${ }^{\circ} 403 / 59$ e de concordar com a Portaria n. ${ }^{\circ} 64$, é ineficaz, por não ter sido feita por quem de direito, como expusemos.

Assim, não há como reconhecer-se legitimidade à liberação do devedor, feita pelo mandatário, que, NÃO TENDO RECEBIDO, NEM TRANSIGIDO, não podia remitir o saldo da dívida, por falta de poderes.

Só há liberação quando a dívida é paga ao credor ou a quem legitimamente o represente, ou então, quando o credor ou seu representante pratique ato extintivo da obrigação. Fora disso e desde que a dívida não esteja prescrita, como no caso, continua o devedor vinculado ao credor pela obrigação que assumiu.

O vínculo existente entre a Fundação B e o Engenheiro Civil
A, relativo ao pagamento do saldo da dívida em aprêço, está íntegro, podendo, em conseqüência, exigílo o credor, com a titularidade de direitos que a execução da obra, devidamente autorizada, lhe conferiu.

Está, assim, respondida a quarta pergunta.

E diante do que está exposto, respondemos negativamente a quinta pergunta.

Já asseverámos que o chamado "têrmo de composição amigável" é ato exorbitante do mandato outorgado.

Sexta pergunta - Não nos foi esclarecido o que consta do protocolado n. $^{\circ} 23 . / 59$, a que se refere a Portaria n. ${ }^{\circ}$ 64, da Fundação B. Contudo, se a execução da obra ajustada com o Engenheiro Civil $\mathbf{A}$ foi feita de acôrdo com a Ordem de Serviço que a determinou, está claro que a providência contida na referida Portaria n. ${ }^{0} 64$ foi tardia e não mais cumpriu sua finalidade, - pois o consulente informa que, na data de sua expedição, a obra já havia sido concluída, entregue e aceita. De tal sorte, se a Fundação B recebeu uma obra, cujo preço total deveria ser calculado segundo as Tabelas do Departamento de Estradas de Rodagem do Estado, e se apenas uma parte do preço foi paga (diretamente ao credor), restando a outra parte da dívida, de que o procurador, SEM PODERES ESPECIAIS, abriu mão, é evidente que o saldo da dívida subsiste e o seu pagamento não pode ser recusado. Tudo, é óbvio, no pressuposto de que a Fundação B recebeu a 
obra executada, como foi contratado.

Negar o direito ao recebimento de tal saldo importa em se admitir o locupletamento à custa alheia. Embora não tenhamos o instituto do enriquecimento ilícito, enriquecimento ilegítimo, enriquecimento seu causa, enriquecimento injusto, também chamado enriquecimento indevido, disciplinado em capítulo especial de nosso Código, ninguém nega que o seu princípio fundamental esteja aplicado, em diferentes institutos ali regidos.

No caso em exame, o locupletamento à alheia custa se verificaria, se a Fundação B não pagasse sua dívida, porque a quitação dada pelo procurador $\mathbf{C}$ é ato ineficaz (art. 141, inc. IV, combinado com os arts. 940 e 1.295 e seu parágrafo $1 .^{\circ}$, do Código Civil). De acôrdo com o mandato outorgado, dita quitação poderia dar-se em conseqüência de pagamento ou ato equivalente, que encerrasse retribuição dos esforços do Engenheiro Civil A. Deu-a o procurador C, como conseqüência da renúncia de direitos que formalizou no chamado "têrmo de composição amigável", porém, sem se achar investido de poderes para tanto. Faltalhe requisito essencial, qual seja o recebimento do preço da obra exe- cutada, uma vez que o escôpo do mandante não foi fazer liberalidades. Não foi para êsse fim que êle constituiu procurador.

Assim, entendemos que a Portaria $n .^{\circ} 64$ não teve qualquer virtude, mòrmente no sentido de eximir a Fundação B, do pagamento de sua dívida. Expedida após a execução da obra, foi, de todo, inócua. $\mathrm{E}$ isto é tão certo que a própria Fundação fez constar, no chamado "têrmo de composição amigável”, a expressa concordância do procurador. Mas, o assentimento dêste à Portaria n. ${ }^{\circ} 64$, e, bem, assim, a retratação do protocolado n. ${ }^{\circ} 403 / 59$, não são influentes para sua vigência, visto contrariarem o objetivo do mandato outorgado. Até pelo contrário, chegam a constituir ofensa aos direitos do empreiteiro (art. 1.247 do Código Civil).

E como respondemos a sexta pergunta.

Quanto à sétima pergunta, a resposta decorre do que já expusemos.

Admitidos os pressupostos da consulta, é irrecusável o direito do Engenheiro Civil A ao recebimento do saldo da dívida atinente à execução da obra ajustada com a Fundação B. 